\title{
SULANCA X MUAMBA \\ rede social que alimenta a migração de retorno
}

Maria Rejane Souza de Britto Lyra

\begin{abstract}
Resumo: Este trabalho analisa o processo de migração de retorno a Pernambuco, procedente do Estado de São Paulo, no período 1970-2000, buscando indícios de redes sociais que se instalam no processo de migração de retorno. Como resultado, o retorno não implicou, para muitos, a perspectiva de tornar a emigrar para São Paulo, caracterizando a reversibilidade do movimento de retorno, inclusive para o Agreste Pernambucano, para onde afluiu o maior volume de retornados.

Palavras-chave: Migração de retorno. Redes sociais. Redes migratórias.

Abstract: This work examines the return migration process to Pernambuco, proceeding from the state of São Paulo, in the period of 1970-2000, treating the migratory flow from the perspective of the social networks. As a result, the return characterize the reversibility of movement to the Agreste Pernambucano, where a lot of migrants returned to.

Key words: Return migration. Social networks. Migratory flow.
\end{abstract}

Todas as sextas-feiras, um posto de gasolina de Caruaru, localizado às margens da BR-104, transforma-se numa verdadeira rodoviária pirata com dezenas de ônibus clandestinos partindo para o Sul e Sudeste do país, sobretudo São

Paulo. Pelo menos três desses ônibus fazem viagens regulares para Foz do Iguaçu, no Paraná, viabilizando a atividade de um novo tipo de mascate cada dia mais comum em Caruaru: o sulanqueiro-muambeiro. São dezenas de homens e mulheres que duas vezes por mês enfrentam três dias de viagem para vender as roupas produzidas em Santa Cruz do Capibaribe e comprar brinquedos, fitas cassete e toda a sorte de bugigangas em Ciudad del Este, paraíso da muamba, vizinho a Foz do Iguaçu. ${ }^{I}$

$\mathrm{H}$ á cerca de doze anos, este circuito, percorrido por esses ônibus clandestinos ${ }^{2}$, parece consolidar uma rede entre nordestinos do Agreste de Pernambuco e moradores do Sul e Sudeste do país, especialmente de São Paulo, já que é nesta cidade onde desce a maioria dos passageiros (85\%), com suas cargas dirigindo- se ao bairro do Brás, indo o restante dos passageiros até a cidade paranaense de Foz do Iguaçu, onde atravessam a Ponte da Amizade para Ciudad del Este, no Paraguai. Nessa travessia, um grupo de pernambucanos atua como "laranja de mão dupla" ${ }^{\prime 3}$ levando sulanca ${ }^{4}$ e trazendo muamba. ${ }^{5}$

Como núcleo do Agreste Pernambucano, o município de Caruaru é ponto inicial dessa rota de ônibus que liga a região a São Paulo e a Foz do Iguaçu, através de um circuito regular de transporte de sulanqueiros e muambeiros com seus produtos para comercializar.

As redes de relações sociais estabelecidas e consolidadas pelo circuito dos ônibus na rota Caruaru-São Paulo-Foz do Iguaçu levam a supor que:

- migrantes pernambucanos residentes em São Paulo alimentam a rede de comércio - formal e informal - estabelecida entre o sul do país e sua terra natal, reforçando sua relação com a família e a própria economia familiar; 
- a rede estabelecida pela rota dos ônibus anteriormente citada propicia o aumento do fluxo de retorno dos migrantes residentes no Sul e Sudeste do país, em especial em São Paulo, seja de forma permanente, caracterizando uma "reversibilidade" do fenômeno da migração, seja de caráter provisório, caracterizando o "ir e vir", ou seja, a "circularidade"7 dos migrantes.

Este texto focaliza a migração de retorno para a Região de Desenvolvimento - RD Agreste Central de Pernambuco, contextualizando-a a partir dos processos instalados no território desse Estado. Evidencia que, surpreendentemente, essa região ultrapassa em termos de volume e taxa média anual de migração de retorno a Região Metropolitana do Recife - o pólo mais dinâmico do Estado - onde se esperaria encontrar uma maior atratividade de retornados. Destaca, como questão central, o papel das redes sociais que ligam os núcleos dinâmicos da região do agreste pernambucano com o Estado de São Paulo e que alimentam a migração de retorno, possivelmente atraída pelas oportunidades econômicas que têm se configurado como alternativa de trabalho e renda naquela região agrestina.

\section{O DESTAQUE DA MESORREGIÃO DO AGRESTE PERNAMBUCANO ATRAINDO MIGRANTES RETORNADOS}

A Mesorregião - MR do Agreste Pernambucano, no contexto estadual, destacou-se ao longo de todo o período analisado, não só como de maior evasão de população ${ }^{8}$ -39,3\% (1970-80) e 33,1\% (1981-91) -, como também de maior atração de migrantes de retorno - 42,5\%, 45,2\% e 41,3\%, nas décadas de 70-80, 81-91 e 90-2000, respectivamente. Enquanto mostrou-se propensa a perder menos população, exibiu, em compensação, a tendência a receber mais retornados (Tabela 1 ).

Ao relacionar o volume dos migrantes de retorno com o contingente populacional, evidenciou-se a expressividade dos pernambucanos da mesorregião do Agreste. Verificouse, dessa forma, que a taxa média anual de migração de retorno superou tanto a média estadual quanto as demais mesorregiões, chegando a triplicar o seu valor em relação à Mesorregião Metropolitana no período 1981-91. Tal condição reafirmou a Mesorregião do Agreste como a de maior intensidade migratória.

Observa-se, no contexto da MR do Agreste Pernambucano, que a RD Agreste Central, da qual o município de Caruaru constitui o centro dinâmico, destacou-se como a de maior volume de retornados. Sua posição de destaque também apresentou as maiores taxas médias anuais de migração de retorno nas duas primeiras décadas, reduzindo, contudo, a distância relativa que a destaca da RD Agreste Meridional nos anos 90.

Para a compreensão desse processo, especialmente quanto às oportunidades de trabalho dos migrantes de retorno, buscou-se identificar alguns elementos de incentivo ou de constrangimento das regiões de desenvolvimento mais expressivas de Pernambuco, capazes de explicar seja a evasão dos migrantes naturais pernambucanos seja a atração dos migrantes de retorno, aprofundando a análise num quadro de mudanças ocorridas no período 1970-2000.

$\mathrm{O}$ enfoque dado às condições de trabalho leva em consideração que "trabalho" e "família" são entendidos como fatores fundamentais na decisão de migrar e constituem duas questões-chave para o entendimento do processo de migração de retorno. Este entendimento é reforçado por Scott (1986), que destaca entre as razões mais fortes que fazem com que tantos migrantes voltem a enfrentar as mesmas condições que deixaram: a exclusão da maioria dos migrantes de retorno da força de trabalho ocupada durante a sua estada fora; a família, mais especificamente, a unidade doméstica, com a qual o migrante sente ligação e que se constitui como o seu veículo de sobrevivência na sociedade.

Reforçando a importância das relações de trabalho, Sayad (2000, p. 8) indaga:

existem migrações, por mais reduzidas que sejam, e por quaisquer que sejam as razões declaradas, que não sejam de trabalho? Isto é, que não tenham implicações no mercado de trabalho?

Pernambuco, com a diversidade de suas regiões, apresenta grande centralização da economia e da população em algumas áreas, bem como expressa significativa desigualdade nos níveis de desenvolvimento e de qualidade de vida. A Região Metropolitana do Recife, que abrange quase $3 \%$ da área do Estado, concentra 42,11\% (1990-2000) da população pernambucana e mais da metade do PIB do Estado, apresentando os seus melhores indicadores sociais. Essa região conta, ainda, com as maiores potencialidades e condições mais efetivas de crescimento e desenvolvimento, tais como a oferta de infra-estrutura e o nível de escolaridade, além da proximidade dos centros universitários existentes em Pernambuco (FIDEM, 1999). Assim, era de se esperar que essa região metropolitana atraísse um maior número de migrantes de retorno interestaduais procedentes do Estado de São Paulo, em vez de eles se dirigirem em maior quantidade para a Região de Desenvolvimento 
TABELA 1

Volume e Taxa Média Anual dos Migrantes de Retorno a Pernambuco

Procedentes do Estado de São Paulo (1), segundo Mesorregiões e Regiões de Desenvolvimento Pernambuco - 1970-2000

\begin{tabular}{|c|c|c|c|c|c|c|c|c|c|}
\hline \multirow{3}{*}{$\begin{array}{l}\text { Mesorregiões e } \\
\text { Regiões de } \\
\text { Desenvolvimento }\end{array}$} & \multicolumn{3}{|c|}{$1970-80$} & \multicolumn{3}{|c|}{$1981-91$} & \multicolumn{3}{|c|}{$1990-2000$} \\
\hline & \multicolumn{2}{|c|}{ Volume } & \multirow{2}{*}{$\begin{array}{c}\text { Taxa }(2) \\
(\% \text { a.a. })\end{array}$} & \multicolumn{2}{|c|}{ Volume } & \multirow{2}{*}{$\begin{array}{c}\text { Taxa (2) } \\
(\% \text { a.a.) }\end{array}$} & \multicolumn{2}{|c|}{ Volume } & \multirow{2}{*}{$\begin{array}{r}\text { Taxa (2) } \\
(\% \text { a.a.) }\end{array}$} \\
\hline & Nos Abs. & $\%$ & & Nos Abs. & $\%$ & & Nos Abs. & $\%$ & \\
\hline PERNAMBUCO & 30.539 & 100,00 & 0,050 & 62.367 & 100,00 & 0,086 & 78.635 & 100,00 & 0,116 \\
\hline MR/RD Metropolitana (3) & 10.469 & 34,27 & 0,050 & 14.984 & 24,03 & 0,052 & 21.106 & 26,84 & 0,075 \\
\hline Núcleo Central & 8.803 & 28,83 & 0,054 & 10.329 & 16,56 & 0,048 & 13.368 & 17,00 & 0,066 \\
\hline Recife & 6.743 & 22,08 & 0,060 & 5.929 & 9,51 & 0,043 & 6.459 & 8,21 & 0,053 \\
\hline Litoral Norte & 914 & 2,98 & 0,051 & 2.349 & 3,77 & 0,068 & 3.534 & 4,49 & 0,090 \\
\hline Faixa Oeste & 589 & 1,93 & 0,039 & 1.516 & 2,43 & 0,069 & 2.600 & 3,31 & 0,119 \\
\hline Litoral Sul & 163 & 0,53 & 0,013 & 772 & 1,24 & 0,045 & 1.604 & 2,04 & 0,093 \\
\hline MR Mata PE & 3.077 & 10,08 & 0,030 & 6.345 & 10,17 & 0,053 & 8.478 & 10,78 & 0,080 \\
\hline RD Mata Norte & 760 & 2,49 & 0,017 & 2.650 & 4,25 & 0,050 & 3.391 & 4,31 & 0,072 \\
\hline RD Mata Sul & 2.317 & 7,59 & 0,042 & 3.695 & 5,92 & 0,056 & 5.087 & 6,47 & 0,087 \\
\hline MR Agreste PE & 12.981 & 42,51 & 0,080 & 28.184 & 45,19 & 0,157 & 32.479 & 41,30 & 0,190 \\
\hline RD A. Setentrional & 1.569 & 5,14 & 0,044 & 3.808 & 6,11 & 0,088 & 6.335 & 8,06 & 0,161 \\
\hline RD A. Central & 7.884 & 25,82 & 0,108 & 15.582 & 24,98 & 0,177 & 14.998 & 19,07 & 0,187 \\
\hline RD A. Meridional & 3.528 & 11,55 & 0,069 & 8.794 & 14,10 & 0,146 & 11.146 & 14,17 & 0,215 \\
\hline MR Sertão PE & 2.870 & 9,40 & 0,040 & 10.796 & 17,31 & 0,118 & 12.893 & 16,40 & 0,159 \\
\hline RD S. Pajeú-Moxotó & 1.932 & 6,33 & 0,048 & 7.721 & 12,38 & 0,155 & 7.967 & 10,13 & 0,185 \\
\hline RD S. Central & 395 & 1,29 & 0,033 & 1.355 & 2,17 & 0,086 & 1.723 & 2,19 & 0,123 \\
\hline RD S. Araripe & 543 & 1,78 & 0,027 & 1.720 & 2,76 & 0,066 & 3.203 & 4,07 & 0,135 \\
\hline MR S. Francisco PE & 1.142 & 3,74 & 0,050 & 2.058 & 3,30 & 0,059 & 3.679 & 4,68 & 0,099 \\
\hline RD Sertão de Itaparica & 491 & 1,61 & 0,056 & 716 & 1,15 & 0,063 & 818 & 1,04 & 0,081 \\
\hline RD São Francisco & 651 & 2,13 & 0,047 & 1.342 & 2,15 & 0,058 & 2.861 & 3,64 & 0,106 \\
\hline
\end{tabular}

Fonte: IBGE. Censos Demográficos 1980 a 2000 (tabulações especiais).

(1) Fluxo interestadual de Migrantes de Retorno SP-PE: corresponde aos migrantes com menos de 10 anos de residência na UF atual (PE), que nasceram em Pernambuco e a última procedência é o Estado de São Paulo.

(2) Taxa média anual de migração de retorno SP-PE, corresponde ao volume de retornados, dividido pelo número de anos do período considerado, dividido pela população projetada para o meio do período de cada região. Deste modo, as Taxas Médias Anuais de Migração de Retorno expressam a relação existente entre este componente do fluxo migratório e a população média no período estudado. Este procedimento não só atende às medidas comparáveis em intervalos diferentes, como mede a atração que as Regiões de Desenvolvimento de Pernambuco exercem sobre os emigrantes pernambucanos residentes em São Paulo.

(3) Os municípios da Meso/RD Metropolitana estão reunidos em sub-regiões geográficas: Núcleo Central (Recife, Olinda, Jaboatão dos Guararapes), Litoral Norte (Paulista, Abreu e Lima Igarassu, Itamaracá, Itapissuma e Araçoiaba), Faixa Oeste (Camaragibe, São Lourenço da Mata e Moreno), Litoral Sul (Cabo e Ipojuca). Os dados do distrito estadual de Fernando de Noronha foram incluídos no total da MR/RD Metropolitana do Recife.

Agreste Central, que, surpreendentemente, ultrapassa em volume e taxa média anual de migração de retorno aquela região. A ampliação das oportunidades de trabalho na MR do Agreste, na década de 80, pode-se colocar como fator de mudança desse comportamento.

A Mesorregião do Agreste Pernambucano ocupa cerca de um quarto do território do Estado, onde se assenta, também, um quarto da população, sendo a única, entre as mesorregiões de Pernambuco, a apresentar taxa de crescimento ascendente. Situada na região de semi-árido do Es- tado, reúne três regiões de desenvolvimento: RD Agreste Setentrional, RD Agreste Central e RD Agreste Meridional. Tem economia caracterizada por exploração agrícola, pecuária e atividades de comércio e serviços associadas aos centros urbanos dinâmicos. A pecuária de corte e de leite tem um grande peso econômico na região, incrementada pela produção artesanal, semi-artesanal e industrial de laticínios, que se destaca como a maior do Estado. Nas áreas de brejo, o cultivo de hortifrutigranjeiros também oferece um suporte à economia regional. 
Desde a década de 70, novas atividades vêm assumindo um papel econômico importante na região, que envolve não só a produção - de roupa (sulanca), de bordados e renda, de artesanato de barro - como também, especialmente, a comercialização dessa produção, através da criação e do incremento de feiras livres - a Feira da Sulanca, em vários locais do Estado, e a Feira de Caruaru. Os eventos turísticos, incentivados pelo poder público em associação a promotores privados, que, em geral, envolvem vários municípios, extrapolando, em alguns casos, a RD onde eles se localizam, também contribuem para a criação de novas oportunidades de trabalho na região. Isso pode, inclusive explicar o destaque da MR do Agreste Pernambucano, no contexto da migração de retorno no Estado.

Um aspecto importante a salientar é que os municípios do entorno de Caruaru oferecem as vantagens da proximidade desse centro dinâmico, ao mesmo tempo em que exibem condições de fixação talvez mais acessíveis ao retornado. Em todo caso, pode-se admitir a influência de Caruaru, seja na atração de migrantes de retorno de outros municípios pernambucanos para o seu espaço, seja na determinação de retornar a um município de origem situado nas vizinhanças de Caruaru.

O maior porcentual dos emigrantes naturais da RD Agreste Central, no período 1981-91, foi encontrado no município de Pesqueira e no seu entorno (32,85\%), do mesmo modo que esses municípios apresentaram o maior retorno do período (34,05\%). Este pólo de muitas saídas e muitas entradas sugere a existência de redes sociais. No conjunto desses municípios destacam-se Belo Jardim, onde estão instaladas indústrias de porte como Palmeiron, Mafisa e Baterias Moura; os municípios de Alagoinha e Poção, onde há uma significativa produção de renda renascença, doces artesanais e indústrias do setor de condimentos; Pesqueira e Poção, por seu turismo religioso (LYRA, 2003).

Nesse sentido, é importante citar Patarra et al. (1997, p. 33), que destacam a elevada mobilidade da população, seja através de fluxos intrametropolitanos ou de fluxos entre a metrópole e o interior, num quadro onde se mantém a expressividade do movimento migratório, seja pelo aumento sensível da emigração de naturais como de não-naturais (inclusive os migrantes de retorno) de São Paulo, seja pela importância relativa dos grandes fluxos migratórios para São Paulo originários do Nordeste. Nesse contexto, os autores apontam para o novo papel que se desenha para as pequenas e médias cidades do sistema urbano paulista, uma vez que de um lado, se consolidam os processos de formação das novas metrópoles do interior [...], bem como ganham nova densidade antigos aglomerados urbanos constituídos por uma trama de cidades articuladas funcionalmente e hierarquicamente dispostas. Este processo é movido sobretudo pela periferização do crescimento populacional destas áreas, tanto no sentido de menores diferenciais entre os ritmos de expansão das sedes regionais e seus entornos, como muitas vezes pelo próprio crescimento mais acentuado das pequenas localidades e do entorno das sedes regionais.

Lyra (2003) constatou uma afluência expressiva de não-naturais desde a década de 70 , crescendo na década de 80, para a região do Agreste pernambucano, em face, especialmente, da produção de sulanca e das feiras livres, inclusive motivados pela expansão e dinamicidade da Feira de Caruaru, ${ }^{9}$ com sua diversidade de produtos e procedimentos. A "feira do troca-troca", por exemplo, é um de seus atrativos, onde não se fala em dinheiro. Tudo é trocado, mesmo sendo os mais absurdos dos negócios. Trocam-se aves por discos, relógios por rádios, bicicletas por animais, móveis, botijões de gás, pássaros, etc. Toda essa diversidade faz da Feira de Caruaru um evento que extrapola a região, alimentando, inclusive, os ônibus clandestinos que ligam essa região a São Paulo.

\section{A ROTA CLANDESTINA DE ÔNIBUS SUGERINDO REDES MIGRATÓRIAS ENTRE PERNAMBUCO E SÃO PAULO}

As informações obtidas, através da reportagem já citada e de entrevista com integrantes do Sebrae, acerca do circuito de ônibus clandestinos que ligam Pernambuco a São Paulo, confirmam uma rede de interações de migrantes pernambucanos estabelecidos em São Paulo com seus parentes e conterrâneos (Mapa 1).

A importância do pólo caruaruense no Agreste pernambucano dá-se pelo comércio dinâmico da cidade, através de sua Feira de Caruaru, onde se insere a Feira do Paraguai. Nelas são comercializadas, entre outros artigos, a sulanca produzida em Santa Cruz do Capibaribe, ${ }^{10}$ os artefatos de couro produzidos em Cachoeirinha, município vizinho a São Caetano, ${ }^{11}$ além de produtos vindos de São Paulo e do Paraguai.

De acordo com os vendedores que trabalham com a mercadoria nas ruas de Ciudad del Este, ${ }^{12}$ as roupas baratas produzidas em Pernambuco e em São Paulo corres- 


\section{MAPA 1}

Circuito de Ônibus do Agreste Pernambucano a São Paulo - Foz do Iguaçu (1)

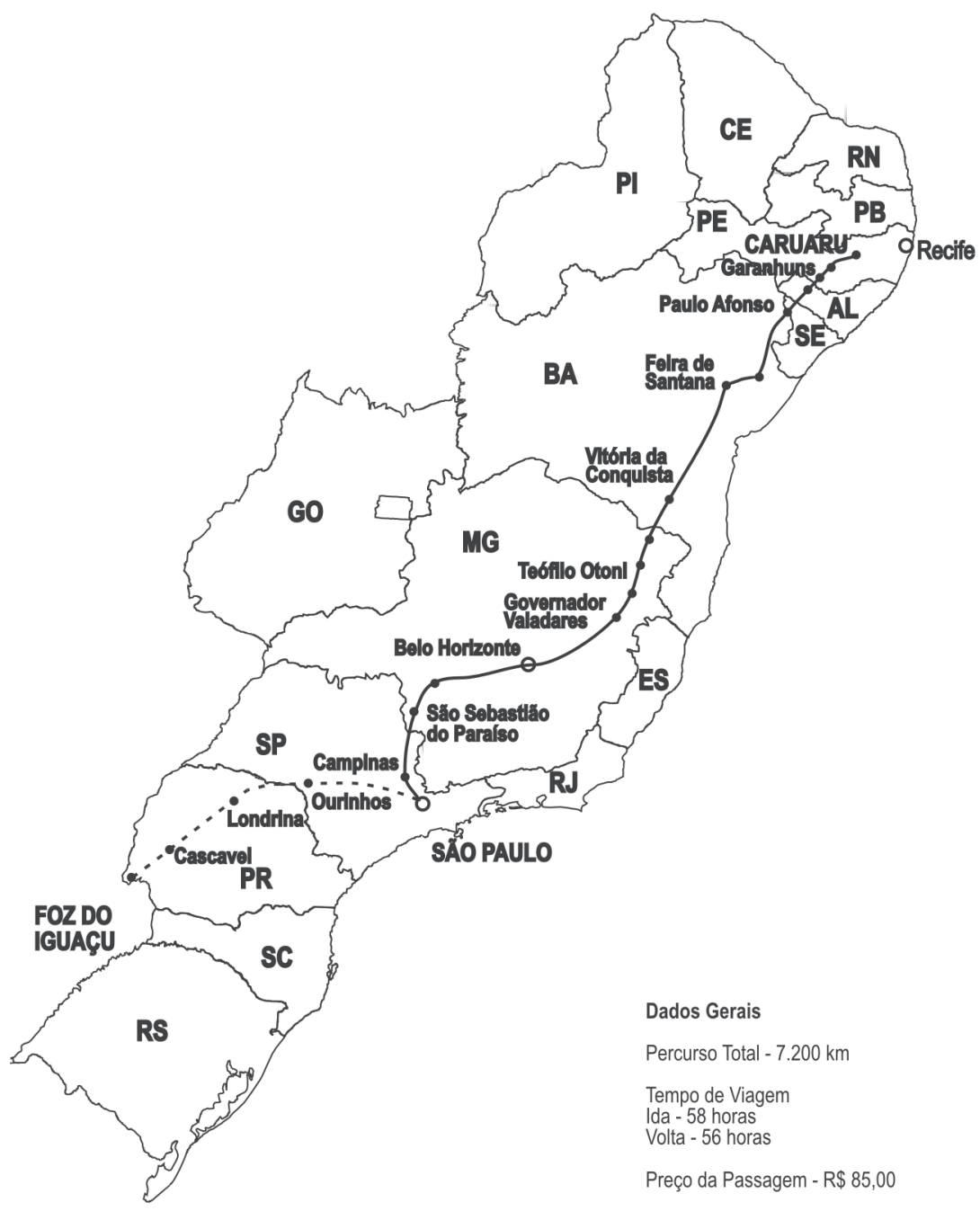

Fonte: Jornal do Comércio, 22 out. 2000

(1) Rota: Caruaru - São Paulo - Foz do lguaçu - São Paulo - Caruaru.

pondem a $30 \%$ dos produtos de vestuário comercializados. Comprada a baixo custo, a mercadoria tem saída certa, alimentando o comércio que se estabelece entre São Paulo e os pólos de produção e comercialização da "sulanca" em Pernambuco.

Tanto as roupas do Nordeste quanto as de São Paulo são muito procuradas porque têm preço baixo e são muito bonitas, apesar de não terem um acabamento muito bom. ${ }^{13}$
Os produtos trazidos de Ciudad del Este vão, na maioria, para os tabuleiros da Feira do Paraguai, em Caruaru, que se inicia todas as segundas-feiras às 20 horas e termina ao meio-dia das terças-feiras, congregando cerca de 3.000 comerciantes e atraindo compradores de todo o interior pernambucano e até de Estados vizinhos. Parte dos produtos são revendidos diretamente em cidades do interior de Pernambuco, na busca de maior lucro pelos mascates. 
Um dado de grande interesse para este estudo, que envolve essa rede de comércio, remete às conexões que se estabelecem entre migrantes pernambucanos em São Paulo e seus parentes do Agreste de Pernambuco. Dona Santina Lima, ${ }^{14} 63$ anos, participa da Feira do Paraguai com mercadorias enviadas por seu filho, residente em São Paulo. Tais produtos são remetidos via transportadora regularizada, o que, por sua vez, sugere uma coexistência de processos formais e informais nesse comércio estabelecido. O vizinho de banca de D. Santina, por exemplo, afirmou que todas as suas mercadorias são compradas com nota fiscal e que ele próprio participa da luta dos feirantes de Caruaru para que se discipline o comércio local.

No outro lado da rede, ou seja, em São Paulo, Rigamonte (1997) aponta para alguns processos que se estabelecem e alimentam os fluxos migratórios. A "Feira do Norte", montada nas imediações da Praça Agente Cícero, diante da Estação Ferroviária Roosevelt, funciona nos moldes de uma feira livre, destacando-se pela variedade de produtos provenientes do Nordeste e comercializados por conterrâneos nordestinos. Aos artigos regionais mistura-se uma infinidade de produtos eletrônicos provenientes do Paraguai, acompanhados por roupas e cosméticos, à semelhança da Feira do Paraguai de Caruaru.

Além dessa feira, outras organizações são estabelecidas por migrantes, promovendo um contato regular interpessoal e facilitando grandemente o processo de adaptação e mútua assistência. A Praça Sílvio Romero, por exemplo, há mais de 30 anos reúne, aos domingos, imigrantes nordestinos que esperam caminhões para trocar mercadorias - presentes, alimentos, dinheiro, cartas, recados - com seu local de origem. Esses migrantes vão até lá, muitas vezes, para conversar com o caminhoneiro recém-chegado, a fim de obter informações recentes sobre a sua região, tais como quem casou, quem morreu, quem migrou, quem retornou, e assim por diante. Essa convivência dominical estreita laços de amizade, motivados pela conterraneidade, e alimenta redes de informações sobre oportunidades de trabalho, nos locais de origem e destino, bem como sobre moradia, lazer, etc. (RIGAMONTE, 1997).

A relação é de confiabilidade e cumplicidade entre os organizadores e os receptores dessa "rede informal de comunicação". Em meio à metrópole e a relações tão distanciadas, há um espaço preservado que reproduz as relações vividas na região de origem, garantindo a sua continuidade. Além da perpetuação dos laços de origem, é possível observar ainda, nesses locais como se deu a formação de um "pedaço" nordestino dentro de pedaços de São Paulo.

O desenvolvimento dos meios de comunicação contribui bastante, facilitando não só a interação das redes de migrantes, como também a decisão de migrar. Nesse sentido, o depoimento de um migrante pernambucano (Edivânio, 66 anos), ${ }^{15}$ aposentado, atesta a diferença que separa o processo por ele vivido, certamente nas décadas de 50-60, e o processo atual:

Hoje, as informações são de conhecimento de todos, no meu tempo a gente não tinha nem TV, não sabia o que ia encontrar pela frente. Alguns nem sabiam o caminho de volta para casa, se desse errado estava tudo perdido. Hoje não, há assistência para todo lado, assim facilita a vida do povo.

O desenvolvimento dos meios de comunicação - viários e informacionais - propicia, por sua vez, a alimentação das redes de relações que conferem maior dinamismo ao fluxo que se estabelece entre os dois Estados - Pernambuco e São Paulo. A migração como processo social envolve, também, um complexo conjunto de mudanças individuais, domésticas e comunitárias.

\section{A PERSPECTIVA DAS REDES SOCIAIS NO ENTENDIMENTO DA MIGRAÇÃO DE RETORNO}

Destacando a relevância das redes sociais no contexto das migrações, Sales (1999) considera que:

As unidades efetivas de migração não são indivíduos nem familias, mas sim grupos de pessoas ligadas por conhecimento, amizade e experiencia de trabalho, as quais, de alguma forma, incorporam a migração como uma alternativa possível a um momento crítico das suas vidas, definidas por TILLY (1990, apud Sales, 1999:36). Daí o porquê de as migrações não se darem de forma aleatória, mas se dirigirem para aquelas poucas localidades com as quais seu lugar de origem tem fortes laços que constituem as tais redes sociais. Uma das formas de expressão dessas redes traduz-se na ajuda mútua, como a moradia temporária aos que chegam e ajuda em conseguir o primeiro emprego. As remessas dos imigrantes aos seus parentes nos locais de origem em muito contribuem para solidificar ainda as redes, à medida que essas remessas são fatores decisivos para a vinda de novos migrantes de uma mesma procedência.

Cunha (1994) compartilha com o mesmo ponto de vista de Sales (1999), quando afirma, a respeito dos deslocamentos populacionais internos na Região Metropolitana de São Paulo, que 
as direções dos mesmos não são aleatórias, já que não dependem apenas do que ocorre nas principais áreas de evasão populacional, mas, também, das condições oferecidas nos municípios de destino.

Dentro de um quadro de referência que leva em conta as redes sociais no processo migratório, Massey et al. (1987, p. 4) consideram que tais mudanças

ocorrem de modo preditivo (antecipado), ordenado e são sensivelmente semelhantes em diferentes comunidades. Agem, ainda, em uníssono, causando um aumento na migração através do tempo. Ao longo do tempo crescem os laços entre áreas emissoras e receptoras criando uma rede social que progressivamente reduz o custo do movimento. As pessoas de uma mesma comunidade se entrelaçam em uma rede de obrigações reciprocas sobre as quais os novos migrantes se apóiam e encontram trabalho na sociedade receptora. A faixa de contatos sociais nesta rede se expande com a entrada de cada novo migrante, encorajando, assim, mais migração e, em última análise, levando, assim, a emergir a migração como um fenômeno de massa. ${ }^{16}$

Em uma pesquisa realizada junto a emigrantes do Agreste Pernambucano (RD Agreste Central) do município de Gravatá para Pirituba, em São Paulo, Cavalcanti (1999, p. 81) destaca a questão do imaginário social como um elemento importante nesse processo, considerando que

a decisão de sair [...] depende seguramente dos laços dos parentes no 'sul'. Esses passam sua experiência para os que chegam e fazem, de certa maneira, uma triagem, selecionando os que devem ser acolhidos e estimulados a ficar e os que devem voltar. Todos aprendem rápido que, para sobreviverem nesse novo espaço urbano, é necessário que o indivíduo adquira novos sistemas de sinais e novos referenciais, os quais precisam ser interiorizados a fim de que possam situarse. O futuro, obviamente, pode ser ampliado ao preço da incerteza e insegurança e da superação de um certo limite, que é dado a cada um pelo sistema de uma cidade organizada, impessoal e exigente de qualidades.

As redes sociais fornecem o apoio psicológico e material necessário aos migrantes. Representam uma forma de capital significativo. Encaminham ao emprego, intermedeiam as comunicações, fazem um tipo de ponte entre as pessoas envolvidas. Geralmente, cada migrante novo, o primeiro a chegar em um lugar, faz crescer uma rede em torno de si, incluindo outras pessoas, migrantes ou não. Essas redes proliferam-se e sustentam-se. Funcionam quase como uma força estrutural. Esse apoio incondicional ficou evi- denciado na pesquisa realizada por Baptista (1998, p. 286), analisando as redes sociais de solidariedade, como tática de resistência e sobrevivência, na vida cotidiana do migrante nordestino residente em São Paulo, que enfrenta a pobreza e a miséria. Entre os depoimentos colhidos pela autora, o de uma migrante nordestina explicita isso:

A ajuda que temos junto aos nossos que moram aqui é grande.

Se não fosse isso eu não teria como estar aqui.

Enfocando as relações estabelecidas nas redes sociais, entendendo estas como facilitadoras da migração, Domenach e Picouet (1990) têm em mente que as relações de parentesco, amizade e conterraneidade encontram-se na base dessas redes. Massey et al. (1987) compartilham dessa opinião, defendendo, ainda, que essas mesmas relações são reforçadas por uma interação regular em associações voluntárias, constituindo-se como uma das bases sociais nas quais as redes sociais se assentam.

Tais bases consistem em laços sociais que ligam a comunidade emissora a pontos específicos das sociedades receptoras. Estes laços sociais, por sua vez, não são criados pelo processo migratório, mas são a eles adaptados e no decorrer do tempo reforçados pela própria experiência comum da migração. As mais importantes relações nas redes sociais são baseadas em parentesco, amizade, conterraneidade, as quais são reforçadas por uma interação regular em associações voluntárias. As diferentes organizações voluntárias servem às funções de coesão dos migrantes e de integração de outras comunidades. Sejam quais forem os seus propósitos, essas associações voluntárias aumentam sua importância para as redes de migração, além das ligações interpessoais acima mencionadas.

As “organizações voluntárias” contribuem para a fixação dos migrantes no local de destino, confirmando um dos princípios das redes sociais, definido, também, por Massey et al. (1987), segundo o qual, independentemente da aparência temporária do fluxo migratório, é inevitável a fixação de alguns migrantes no seio da sociedade receptora. Os migrantes podem começar como trabalhadores sazonais, mas, com o correr do tempo, adquirem laços sociais e econômicos que os lançam na condição de residência permanente. Estes migrantes formam comunidades afiliadas, coesas dentro da sociedade receptora, as quais fortalecem grandemente as redes na medida em que proporcionam um sólido ancoradouro para relações sociais fora do local de origem, criando um contexto seguro aos quais os migrantes podem chegar e ajustar-se. Isso leva Albuquerque Jr. (1990, p. 32) a afirmar que tal resistência cultural leva, em com- 
pensação, o migrante a colocar a sua marca no processo onde se insere,

estabelecendo limites, abrindo brechas nas quais puderam preservar aspectos de seu modo de vida tradicional: suas festas, seus divertimentos, seus amores, afetos, ódios e valores.

Algumas pesquisas fornecem exemplos ricos do funcionamento das redes sociais para populações que migram. Demonstram que as redes na migração têm um papel tanto viabilizador da saída como territorializador, ou seja, de inserção do migrante no local de destino. Bilac (1997, p. 70) afirma:

Correntes migratórias são estimuladas pelas redes sociais baseadas em laços familiares domésticos de amizade e comunitários. Ligando migrantes e não-migrantes em uma complexa teia de relações sociais e interpessoais, tais redes conduzem informação, assistência social e financeira. Elas também modelam os efeitos da migração - desde a nãomigração, a imigração, a migração de retorno e a continuidade dos fluxos migratórios.

Segundo Massey et al. (1987), a rede impulsiona e faz com que a pessoa migre. Estar dentro da rede significa maior probabilidade de migrar. Se as redes não existissem, as barreiras tornar-se-iam mais fortes e as migrações não seriam tão intensas.

Para a maioria dos migrantes de longa distância, é importante a informação para as decisões de migrar, bem como aquelas redes de assistência para a fixação no destino. Diante dos constrangimentos causados pelas redes pessoais, considerando falhas muitas das vantagens teoricamente disponíveis nos locais de destino, os migrantes concentram-se em algumas localidades nas quais têm fortes ligações com o lugar de origem. O alto risco e o grande custo do retorno tornam mais intensas a confiança nos laços estabelecidos previamente.

Povoa-Neto (1997, apud Batista, 1998), abordando os limites dos troncos teóricos através dos quais a questão das migrações vem sendo analisada e a necessidade de compreensão de fenômenos e processos pouco estudados, finaliza dando relevância às redes:

Tudo parece indicar que, na conjuntura da crise, as redes de relações sociais primárias tendem a representar um apoio ainda mais fundamental àqueles que buscam se estabelecer em um dado lugar ou se encontram simplesmente de passagem. [...] A presença dessas redes de contato, cristalizadas ao longo de décadas de migrações, contribui para explicar a intensidade dos deslocamentos populacionais mesmo em uma situação social em que os diferenciais de renda e de condições de vida se tornam pouco perceptiveis. Tais redes se tornam forças sociais vivas, a estabelecer "pontes" entre os lugares e a permitir ofluxo de informações e de pessoas que fizeram da mobilidade geográfica a sua principal estratégia de sobrevivência.

Baptista (1998), por sua vez, chama atenção para o destaque que Povoa-Neto dá para tais diferenças, as quais, segundo a teoria das migrações mais tradicional, seriam os principais motivadores da decisão de migrar.

\section{CONSIDERAÇÕES FINAIS}

Retomando algumas apreciações feitas ao longo do texto, pode-se dizer que, no contexto das três décadas analisadas (1970-2000), sabe-se que na crise de 1980, fatores estruturais - por exemplo, as limitações do mercado de trabalho, acarretando desemprego e subemprego; a diminuição do poder aquisitivo da população; entre outros fatores aliados à precária qualificação do contingente migratório - passaram a interferir na dinâmica demográfica regional nordestina, à medida que espaços que historicamente se caracterizavam pelo seu poder atrativo de migrantes, a exemplo do Estado de São Paulo, não foram mais capazes de reter o migrante no lugar de destino.

Nesse cenário de retorno ou de redução dos fluxos migratórios pernambucanos, a MR do Agreste Pernambucano foi a região de troca migratória mais expressiva com o Estado de São Paulo. Ao mesmo tempo em que ela se converteu na região que mais expulsou sua população para a terra paulista, ela foi também a que mais recebeu os retornados, chegando a superar a MR/RD Metropolitana do Recife, onde era de se esperar uma maior absorção, considerando seu grau de dinamismo socioeconômico.

A mudança da tendência apresentada pela RD Agreste Central, que passou, da década de 70 para a de 80 , de área expulsora para área de absorção do contingente migratório de retorno, pode ser explicada por alguns fatores dinamizadores que ocorreram na região: novas oportunidades de trabalho, especialmente na década de 80, aumento da produção artesanal com a respectiva dinamização do comércio e dos serviços, associados a eventos turísticos que envolvem vários municípios da região. Esses elementos de incentivos ou constrangimentos, seja na área de origem seja na área de destino, certamente influíram no processo de remigração da população. 
O que tudo indica é que a diversificação das atividades econômicas, que vêm se expandindo, a partir dos anos 70, atraiu os retornados que empreenderam esse movimento de "ir e vir", alimentado por redes sociais que ligaram núcleos dinâmicos dessa região do Agreste pernambucano com a Região Metropolitana de São Paulo. A consolidação dessas atividades na RD Agreste Central, na década de 80, em contrapartida, influenciou provavelmente o comportamento do fluxo migratório que afluiu para a região, ampliando o número daqueles que retornaram para fixar residência.

Apesar de os indícios do movimento de "ir e vir" terem sido expressivos no fluxo migratório analisado, o que se pode concluir é que, para muitos, o retorno não implicou necessariamente a perspectiva de tornar a emigrar para São Paulo, caracterizando a reversibilidade do movimento de retorno, inclusive para a RD Agreste Central, para onde afluiu o maior volume de retornados.

As alternativas de ocupação que vêm emergindo, especialmente nos municípios do Agreste Pernambucano, e que se articulam no entorno do núcleo dinâmico da RD Agreste Central, oferecem um quadro de possibilidades para investigar tal hipótese: Santa Cruz do Capibaribe, como grande produtor de vestuário (sulanca); Cachoeirinha, como produtor de artefatos de couro - sapatos, botas, bolsas, selas, tapetes, etc.; Caruaru, como grande centro de comercialização desses produtos e pólo da rede estabelecida entre o Agreste de Pernambuco e São Paulo, estendendo-se a Foz do Iguaçu. Possivelmente, tal rede seria capaz de responder a Moura (1999, p. 144) quando, a respeito dos migrantes nordestinos de retorno à sua terra natal, ele indaga: "Mas a que novas válvulas de escape poderia a população do Nordeste recorrer para sobreviver?".

\section{NOTAS}

Este trabalho faz parte da tese de doutorado da autora (LYRA, 2003), sob a orientação do Prof. Dr. José Marcos Pinto da Cunha. Comunicação apresentada no Seminário "Quantos Somos e Quem Somos no Nordeste?", realizado pela Fundação Gilberto Freyre, no período de 26 a 28 de abril de 2004. Recife, PE.

1. Trecho de reportagem de Eduardo Machado apresentada no Jornal do Comércio (2000, p. 1-4).

2. A rota percorrida por esses ônibus pelo interior do Brasil inclui trechos onde a estrada "simplesmente sumiu", como a de Ouro Branco, em Alagoas até Jeremoaba, na Bahia. Esses ônibus são adaptados para comportar a maior quantidade possível de carga, retirando, para isso, as três últimas fileiras de bancos traseiros e o próprio banheiro.

3. "Laranjas de mão dupla" são pessoas contratadas pelos sulanqueiros-muambeiros para carregar mercadorias na travessia da Ponte da Amizade, que liga Foz do Iguaçu a Ciudad del Este, visando "driblar" a fiscalização.

4. Roupas produzidas, em geral de forma artesanal e utilizando retalhos variados, no município de Santa Cruz do Capibaribe, situado no Agreste de Pernambuco, limítrofe com o município de Caruaru.

5. Produtos importados, adquiridos, no caso específico, em Ciudad del Este, no Paraguai, e, na sua maioria, sem regularidade fiscal.

6. A "reversibilidade" dos fluxos pode ser definida como o lugar ou conjunto de lugares a partir do qual os deslocamentos têm a probabilidade de retorno mais elevada, uma vez que reforça a condição da primeira residência, do local de nascimento (DOMENACH; PICOUET, 1990, p. 53).

7. "Circularidade" remete ao processo migratório de "ir e vir" e pode referir-se tanto aos indivíduos quanto aos fluxos (CUNHA, 1998, p. 38).

8. Segundo Lyra (2003), os emigrantes pernambucanos totalizaram $289.382(1970-80)$ e 242.295 (1981-91).

9. A Feira de Caruaru reúne, em $40.000 \mathrm{~m} 2$ de área destinada exclusivamente aos comerciantes, fabricantes e feirantes, a Feira Livre, a Feira da Sulanca, a Feira dos Importados (Feira do Paraguai), a Feira do Artesanato e a Feira do Gado. Dentro desse espaço, existe, ainda, um açougue com 306 boxes internos e 43 boxes externos, além de um Mercado de Farinha com 27 boxes internos e 80 boxes externos.

A Feira da Sulanca, com uma quantidade superior a 10.000 bancas cadastradas, mais uma média de $20 \%$ de sulanqueiros sem lugar certo e preços altamente competitivos, onde se compram roupas a partir de $\mathrm{R} \$ 1,00$, é a mais famosa e mais conhecida feira do Estado. Cada dia, mais e mais pessoas a visitam, vindas de cidades vizinhas ou do exterior, em busca do grosso ou varejo. São em média 400 ônibus e 40.000 pessoas por feira. Conforme pesquisa realizada por técnicos de uma consultoria, apuraram-se os seguintes resultados:

- Consumidores: $10 \%$ são de Caruaru, $40 \%$ de outras cidades do interior, $14 \%$ de outros Estados, como Alagoas e Paraíba, 6\% vêm de outros países (Paraguai, por exemplo) e o restante $(30 \%)$ vem de outros Estados;

- Comerciantes/compradores/produtos: 98\% dos compradores vêm todas as semanas à feira; $83 \%$ vêm por causa dos baixos preços dos produtos; $68 \%$ dos comerciantes residem em Caruaru; $37 \%$ das mercadorias são fabricadas na cidade; $64 \%$ das mercadorias vendidas são confecções;

- Vendas: $87,5 \%$ das vendas são feitas em dinheiro; $8,25 \%$ são efetuadas em cheques pré-datados; $4,25 \%$ são com cheques à vista. Calcula-se ainda que em cada feira comercializa-se em média R\$ 1 milhão; adicionalmente, foram identificados 1.294 carroceiros para posterior cadastro (Fonte: <www.feiradecaruaru.com.br>).

10. Conforme informação do Sebrae, Santa Cruz do Capibaribe possui mais de 3.000 unidades produtivas.

11. O município de São Caetano se situa entre Caruaru e Cachoeirinha. Como verificou Lyra (2003), São Caetano e Santa Cruz do Capibaribe, onde se localiza a grande produção de "sulanca", ambos vizinhos a Caruaru, apresentam os mais altos índices de eficácia migratória entre os municípios do Estado de Pernambuco, o que é indicador de uma absorção de população significativa.

12. Conforme entrevista dos repórteres do Jornal do Comércio com os comerciantes da sulanca, em Caruaru.

13. Afirma Feliciana Espinoza, dona de uma loja na Galeria Vênus em Ciudad del Este. 
14. Pseudônimo dado pelos repórteres do Jornal do Comércio a uma barraqueira da Feira do Paraguai, em Caruaru.

15. Entrevista realizada por Rigamonte (1997, p. 51).

16. Tradução da autora.

\section{REFERÊNCIAS BIBLIOGRÁFICAS}

ALBUQUERQUE JR., D.M. de. Paraíbas e bahianos: órfãos de campo, filhos legítimos da cidade. Revista Travessia: Revista do Migrante, São Paulo, CEM, ano III, n. 8, set./dez. 1990.

AMARAL, A.E.P.; NOGUEIRA, R.A.M. A volta da Asa Branca: um estudo sobre migração de retorno a Pernambuco. Recife: Fundaj/Facepe, 1993.

ANDRADE, M.C. de. Dinâmica das microrregiões de intensa atividade migratória. Recife: Sudene/UFPE, 1980. v. 3.

ARAÚJO, T.B. de. Ensaios sobre o desenvolvimento brasileiro: heranças e urgências. Rio de Janeiro: Ed. Revan/Fase, 2000. 392 p.

BAPTISTA, D.M.T. Nas Terras do "Deus-Dará": nordestinos e suas redes sociais em São Paulo. Tese (Doutorado em Ciências Sociais) - Pontifícia Universidade Católica de São Paulo, São Paulo, 1998.

BILAC, E.D. Arranjos domésticos e condição migratória. In: PATARRA, N.; BAENINGER, R.; BÓGUS, L.M.; JANNUZZI, P. (Org.). Migrações, condições de vida e dinâmica urbana: São Paulo 1980-1993. Campinas: Unicamp/IE, 1997. p. $177-$ 268 .

BRANCO, A. de M. Luta e visibilidade numa situação de desastre. João Pessoa: UFPB/Editora Universitária, 2000.

CAIADO, A.S.C. Migração e rede urbana: estudo da mobilidade demográfica nas principais aglomerações urbanas do Estado de São Paulo na década de 90. In: ENCONTRO NACIONAL DE ESTUDOS POPULACIONAIS, 14., Anais... Caxambu, Abep, 2004

CARVALHO, J.A.M.; MACHADO, C.C. Quesito sobre migrações no Censo Demográfico de 1991. Revista Brasileira de Estudos Populacionais, São Paulo, v. 9, n. 1, jan./jun. 1992 .

CAVALCANTI, H. Imaginário social e práticas de saída da pobreza: o povoado de São Severino "dos macacos". Tese (Doutorado em Psicologia Social) - Universidade de São Paulo, São Paulo, 1999.

COURGEAU, D. Nuevos Enfoques para Medir La Movilidad Espacial Interna de La Población. Santiago: Celade, 1990.

CUNHA, J.M.P. (Des)continuidade no padrão demográfico do fluxo São Paulo/Bahia no período 1970/1991: Qual o efeito da crise? In: ENCONTRO NACIONAL DE ESTUDOS POPUlACIONAIS, 11., Anais... Caxambu, Abep, 1998.

Mobilidade populacional e expansão urbana: o caso da Região Metropolitana de São Paulo. Tese (Doutorado em Demografia) - Unicamp/IFCH, Campinas, 1994.
DOMENACH, H.; PICOUET, M. El Caracter de Reversibilidad en el Estudio de la Migración. Notas de Población, Santiago do Chile, Celade, n. 49, 1990

FIDEM - Fundação de Desenvolvimento Municipal. Programa Governo nos Municípios. Regiões de Desenvolvimento. Recife: 1999.

JATOBÁ, J. Mercado de trabalho e crise: o caso do Nordeste, 1981-1983. In: ENCONTRO NACIONAL DE ESTUDOS POPUlACIONAIS, 4., Anais... Águas de São Pedro, Abep, v. 2, 1986. p. 983-1001.

JORNAL DO COMÉRCIO, Recife, 22 out. 2000, Caderno JC Cidades, p. 1-4

LYRA, M.R.S. de B. O processo de migração de retorno no fluxo Pernambuco-São Paulo-Pernambuco. Tese (Doutorado em Demografia) - DS/IFCH/Unicamp, Campinas, 2003.

MASSEY, D.; ALARCÓN, R.; DURAND, J.; GONZÁLEZ, H. Return to Aztlan: The social process of international migration from western Mexico. California: University of California Press, Ltd., 1987.

MATOS, R.; BRAGA, F. Redes sociais, redes territoriais e migraçoes. In: ENCONTRO NACIONAL DE ESTUDOS POPULACIONAIS, 14., Anais... Caxambu, Abep, 2004.

MELO, M.L. de. Os agrestes - Estudos dos espaços nordestinos do sistema gado-policultura de uso dos recursos. Recife: Sudene, 1982 .

MENEZES, M.A. de. Redes e enredos nas trilhas dos migrantes: um estudo de famílias de camponeses - migrantes. Rio de Janeiro: Relume Dumará; João Pessoa: EDUFPB, 2002.

MOREIRA, M. de M. Nordeste: evolução da população e questão social. In: ENCONTRO NACIONAL DE ESTUDOS

POPUlACIONAIS, 7., Anais... Caxambu, Abep/CNPQ, v. 2, 1990. p. 397.

MOURA, H.A. de. A migração nordestina em período recente 1981/1996. Cadernos de Estudos Sociais, Recife, Fundaj, v. 15, n. 1, p. 101-148, jan./jun. 1999.

Nordestinos vivem fenômeno da "migração de retorno" à região. Jornal Diário de Pernambuco. Recife, 1996 (Reportagem de Ayrton Maciel).

A identificação do migrante de retorno através da informação censitária. In: Seminário "Nordeste: Diferenciais Demográficos e seus Determinantes”. Recife, Abep/Fundaj, 1984

PACHECO, C.A.; PATARRA, N. Movimentos migratórios anos 80: novos padrões? In: PATARRA, N.; BAENINGER, R.; BOGUS, L.M.; JANNUZZI, P. (Org.). Migrações, condições de vida e dinâmica urbana: São Paulo 1980-1993. Campinas: Unicamp/IE, 1997. p. 25-52.

PATARRA, N. et al. Dinâmica regional recente: o caso de São Paulo. In: ENCONTRO NACIONAL SOBRE MIGRAÇÃO, 1. 1997, Curitiba, Anais... Curitiba: Abep/Ipardes/CNPq, 1997. p. 31-65. GT Migração.

PORTES, A. Economic Sociology and the Sociology of Immigration: A conceitual overview. In: The Economic Sociology of Immigration. New York: Russel Sage Fundation, 1995.

RIBEIRO, J.T.L.; CARVALHO, J.A.M.; WONG, L.R. Efeitos demográficos da migração de retorno: uma proposta metodológica. In: ENCONTRO NACIONAL DE ESTUDOS POPULACIONAIS, 10., Anais... Abep, v. 2, 1996. p. 955. 
RIGAMONTE, R.C. A Praça Sílvio Romero: a "tradição" Travessia: Revista do Migrante. São Paulo, Centro de Estudos Migratórios - CEM, ano XII, n. 35, p. 37-42, set./dez. 1997.

SALES, T. Brasileiros longe de casa. São Paulo: Cortez, 1999.

Agreste, Agrestes: transformações recentes na agricultura nordestina. São Paulo, Paz e Terra, 1982. (Série Cadernos Cebrap, n. 36).

SAYAD, A. Retorno: elemento constitutivo da condição do imigrante. Travessia: Revista do Migrante. São Paulo, Centro de Estudos Migratórios - CEM, ano XIII, jan. 2000. (edição especial).

SCOTT, R.P. O retorno ao Nordeste: refugo, família e reprodução. In: ENCONTRO NACIONAL DE ESTUDOS
POPUlACIONAIS, 4., Anais... Águas de São Pedro, Abep, v. 2, 1986.

Recife: UFPE, 1983. (Relatório de Pesquisa).

Maria Rejane Souza de Britto Lyra: Socióloga, estatística e demógrafa.

Artigo recebido em 26 de setembro de 2005 .

Aprovado em 21 de novembro de 2005. 